\title{
Congenital sucrase-isomaltase deficiency: identification of a common Inuit founder mutation
}

\author{
Julien L. Marcadier MD, Margaret Boland MD, C. Ronald Scott MD, Kheirie Issa MD, Zaining Wu, \\ Adam D. McIntyre BSc, Robert A. Hegele MD, Michael T. Geraghty MD, Matthew A. Lines MD
}

See also research article on page E68 and at www.cmaj.ca/lookup/doi/10.1503/cmaj.140840 and commentary on page 93 and at www.cmaj.ca /lookup/doi/10.1503/cmaj.141509

Competing interests: None declared.

This article has been peer reviewed.

The authors have obtained patient consent.

Correspondence to:

Matthew Lines,

mlines@cheo.on.ca

CMAJ 2015. DOI:10.1503

/cmaj.140657

\begin{abstract}
Background: Congenital sucrase-isomaltase deficiency is a rare hereditary cause of chronic diarrhea in children. People with this condition lack the intestinal brush-border enzyme required for digestion of di- and oligosaccharides, including sucrose and isomaltose, leading to malabsorption. Although the condition is known to be highly prevalent (about $5 \%-10 \%$ ) in several Inuit populations, the genetic basis for this has not been described. We sought to identify a common mutation for congenital sucrase-isomaltase deficiency in the Inuit population.
\end{abstract}

Methods: We sequenced the sucrase-isomaltase gene, $S I$, in a single Inuit proband with congenital sucrase-isomaltase deficiency who had severe fermentative diarrhea and failure to thrive. We then genotyped a further 128 anonymized Inuit controls from a variety of locales in the Canadian Arctic to assess for a possible founder effect.
Results: In the proband, we identified a novel, homozygous frameshift mutation, c.273_274delAG (p.Gly92Leufs*8), predicted to result in complete absence of a functional protein product. This change was very common among the Inuit controls, with an observed allele frequency of $17.2 \%$ (95\% confidence interval [CI] 12.6\%-21.8\%). The predicted Hardy-Weinberg prevalence of congenital sucrase-isomaltase deficiency in Inuit people, based on this single founder allele, is $3.0 \%(95 \% \mathrm{Cl} 1.4 \%-4.5 \%)$, which is comparable with previous estimates.

Interpretation: We found a common mutation, SI c.273_274delAG, to be responsible for the high prevalence of congenital sucraseisomaltase deficiency among Inuit people. Targeted mutation testing for this allele should afford a simple and minimally invasive means of diagnosing this condition in Inuit patients with chronic diarrhea.

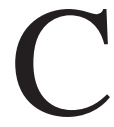

ongenital sucrase-isomaltase deficiency (Online Mendelian Inheritance in Man database no. \#222900; www.omim.org /entry/222900) is a rare autosomal recessive form of carbohydrate malabsorption caused by reduced or absent activity of sucrase-isomaltase, a heterodimeric intestinal brush-border enzyme required for digestion of di- and oligosaccharides, including sucrose and isomaltose (Figure 1). In infants and children with this condition, exposure to specific carbohydrates, such as sucrose, results in profound fermentative diarrhea, gaseous abdominal distention, malabsorption, malnutrition and failure to thrive., ${ }^{1,2}$ Presentation is generally after weaning, due to the introduction of sucrose-containing foods such as fruits; affected people may "self-treat" by developing a dislike of sweet foods. Because symptoms tend to improve with age, adoles- cents and adults with undiagnosed congenital sucrase-isomaltase deficiency may be misdiagnosed with irritable bowel syndrome. ${ }^{3-5}$ If the condition is recognized, relief can be obtained by limiting the offending sugars, for instance, by giving a carbohydrate-free infant formula, and/or by oral digestive enzyme replacement (e.g., sacrosidase). ${ }^{6,7}$

Although congenital sucrase-isomaltase deficiency is rare (about $0.2 \%$ ) in North Americans of European ancestry, ${ }^{8}$ it is relatively common in northern regions. The prevalence in Inuit people in Greenland has been estimated to be as high as 5\%-10\% in studies from 1972 and 1987.9,10 In the region now known as Nunavut, the combined prevalence of congenital sucraseisomaltase deficiency at 2 sites (Repulse Bay and Chesterfield Inlet) has been estimated at $7 \%$ in a study from $1978 .{ }^{11}$ Small case series further 
support a high prevalence of sucrose malabsorption in locales as geographically dispersed as northern Alaska, the northwest coast of Hudson Bay and southern Manitoba. ${ }^{12,13}$

The current diagnostic gold standard for congenital sucrase-isomaltase deficiency is demonstration of complete or near-complete absence of sucrase and/or isomaltase activity in biopsy tissue of the small bowel. ${ }^{14}$ This method is direct, but it is also invasive and poses technical challenges in young patients. Also commonly used are the oral sucrose tolerance test and hydrogen breath test, in which blood glucose and breath hydrogen, respectively, are measured after an oral sucrose load. ${ }^{15}$ Of note, oral sucrose loading inevitably provokes acute abdominal discomfort and diarrhea in patients with this condition. A third option, a therapeutic trial of carbohydratefree foods, provides a clinically meaningful demonstration of disordered carbohydrate digestion, but is not sufficiently specific to be diagnostic of congenital sucrase-isomaltase deficiency. Lastly, genetic testing of $S I$, the gene for this condition, is now clinically available. To date, the Human Gene Mutation Database contains a total of 16 SI mutations. ${ }^{16}$ In people of European descent, 4 mutations account for most disease alleles. ${ }^{17}$ We sought to identify a common mutation for congenital sucrase-isomaltase deficiency in the Inuit population.

\section{Methods}

\section{Patient description}

The proband, a female newborn from Baffin Island, Nunavut, was admitted to hospital 5 days after birth for hemodynamic and ventilatory support in the context of suspected sepsis. Pregnancy and delivery history were unremarkable apart from slight prematurity ( $35 \mathrm{w}, 3 \mathrm{~d}$ ). Bottle feeding with a standard cow's-milk-based infant formula was established soon after birth. On day 5 , the patient was brought to the local nursing station with decreased alertness, hypotonia and hypothermia. During medical evacuation to Ottawa, she required multiple fluid boluses for refractory hypotension. The patient received aggressive treatment, including 7 days of intravenous antibiotics, for suspected pneumonia. By 9 days after birth, her condition had improved such that feeding with a standard premature formula was restarted. Over the following 3 days, abdominal distention (Figure 2) and copious watery diarrhea developed; these symptoms persisted despite a switch to elemental formula. Multiple routine investigations to ascertain the cause of the infant's diarrhea were unrevealing. Evidence of an ongoing malabsorptive process included failure to thrive despite hypercaloric feeding $(190 \mathrm{kcal} / \mathrm{kg} / \mathrm{d})$, increased stool osmotic gap and transient improvement of symptoms

\section{A. Sucrose}

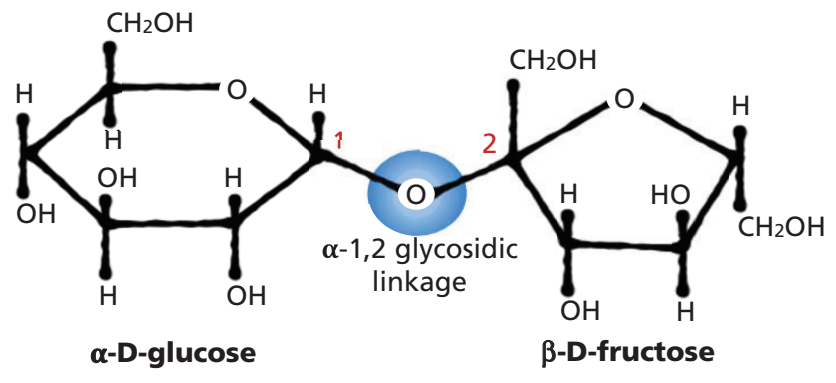

B. Maltose

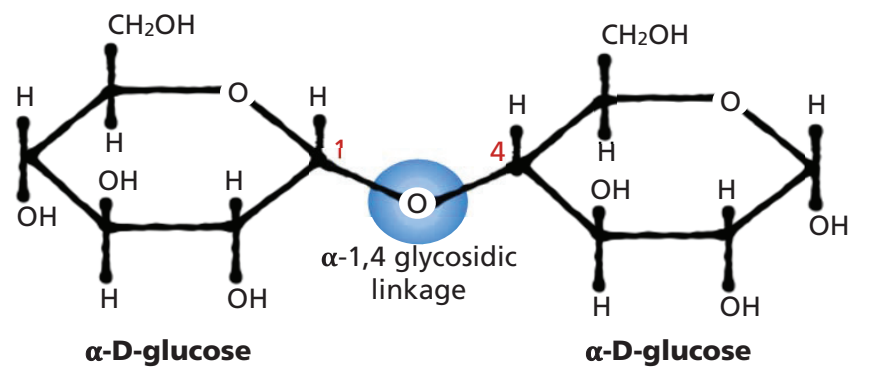

\section{Isomaltose}

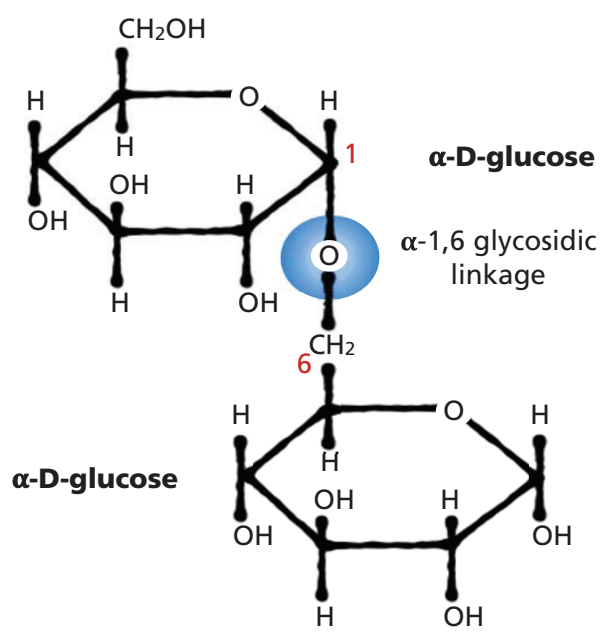

Figure 1: Sucrase-isomaltase catalyzes the hydrolysis of the $\alpha-1,2$ glycosidic bond in sucrose (A), $\alpha-1,4$ glycosidic bond in maltose (B) and $\alpha-1,6$ glycosidic bond in isomaltose (C), as well as $\alpha-1,4$ and $\alpha-1,6$ limit dextrins generated from dietary starch by $\alpha$-amylase (not depicted). Blue circles depict sites of hydrolysis. 
with brief bowel rest. Congenital sucraseisomaltase deficiency was considered at 3 months of age, and a therapeutic trial of carbohydrate-free formula was started, resulting in stools rapidly returning to normal within 48 hours. The patient was discharged on a carbohydrate-free formula with additional dextrose supplementation. At last clinical follow-up (age $5 \mathrm{mo}$ ), the patient was asymptomatic and thriving, and her weight was between the 50th and 75 th centiles for her age.

\section{Control samples}

Hypothesizing a common founder allele among Inuit people, we genotyped 128 anonymized samples from Inuit controls from a range of Canadian Arctic locales. The samples were collected from healthy controls, who self-identified as Inuit, as part of several independent studies screening for cardiovascular risk factors in healthy populations. Controls were geographically equally distributed from the western (Inuvialuit), central (Kivalliq) and eastern (Nunavik) Canadian High Arctic. Information regarding current or past gastrointestinal disease was not available.
Sequencing of the $S /$ gene in the proband Genomic DNA was isolated from whole blood using standard methods. Primers were designed for each of the 48 exons of the SI gene and included the flanking intron boundaries. Each exon and its flanking regions were amplified using polymerase chain reaction (PCR), and the subsequent amplified nucleotides were sequenced using a 3130 Genetic Analyzer (Applied Biosystems). Sequencing software was used to confirm the sequence against the GenBank entry NM_001041.3. The nucleotide of the translation initiation codon ATG constituted numbering 1 of the complementary DNA sequence. We followed the standard naming convention of the Human Genome Variation Society.

\section{Genotyping of control samples}

Genomic DNA samples isolated from whole blood were used in PCR amplifications that were performed employing oligonucleotide primers flanking the variant of interest in the SI gene. Polymerase chain reaction was carried out in $30-\mu \mathrm{L}$ mixtures containing 32 pmol of each primer (sequences available in Appendix 1, available at www.cmaj.ca/lookup/suppl/doi :10.1503/cmaj.140657/-/DC1), $0.2 \mathrm{mM}$ each of
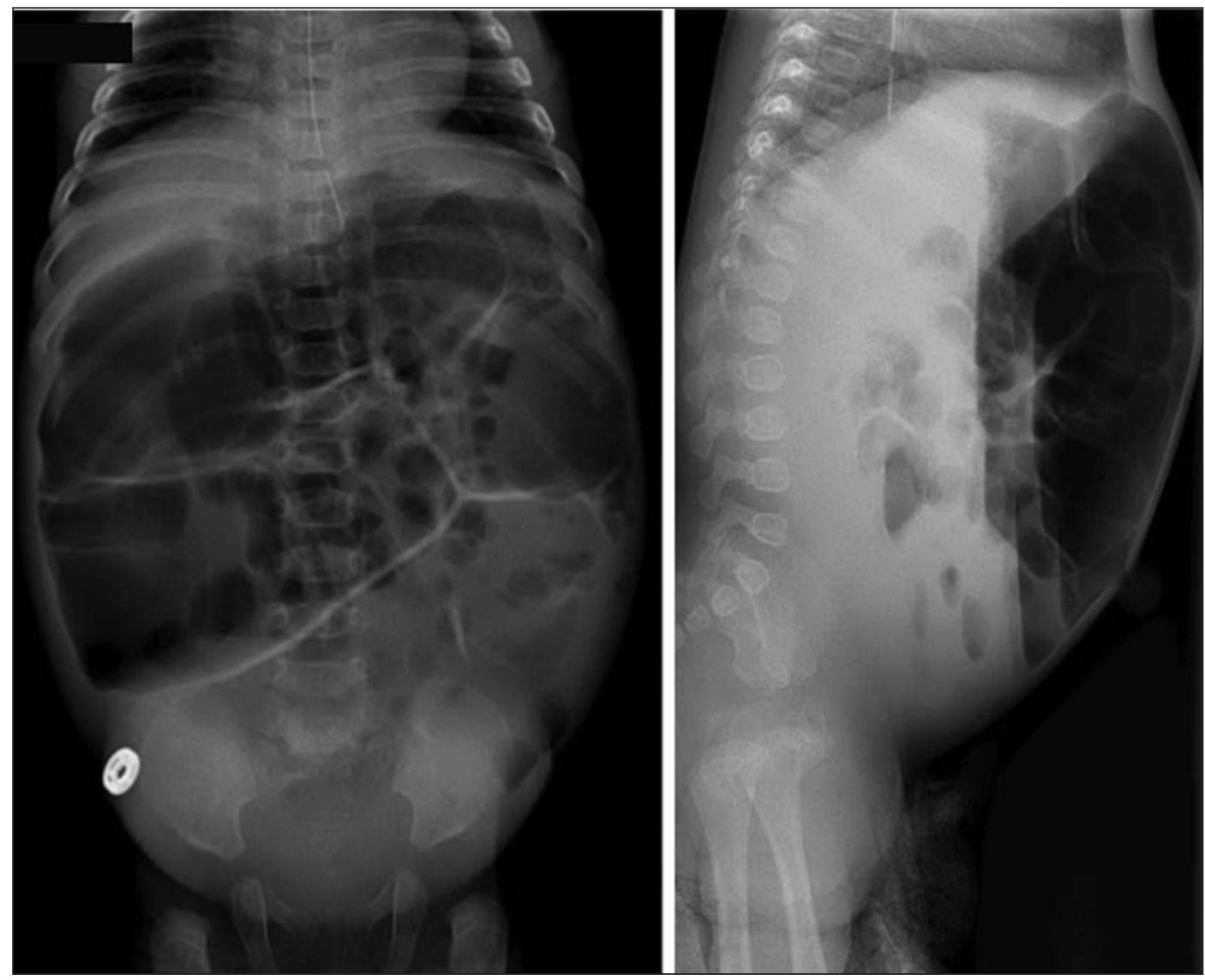

Figure 2: Abdominal radiographs taken at 3 months of age showing severe bowel distension with multiple air-fluid levels in the small bowel. Severity of symptoms was such that the patient received a rectal biopsy for suspected Hirschsprung disease. 
deoxyadenosine triphosphate, deoxycytidine triphosphate, deoxyguanosine triphosphate and deoxythymidine triphosphate, $1.5 \mathrm{mM}$ magnesium chloride, $50 \mathrm{mM}$ potassium chloride, $20 \mathrm{mM}$ tromethamine hydrochloride $(\mathrm{pH} 8.4)$ and 1.0 units of Platinum Taq DNA polymerase (Invitrogen). Thirty amplification cycles were performed, consisting of denaturation at $95^{\circ} \mathrm{C}$, annealing at $60^{\circ} \mathrm{C}$ and extension at $72^{\circ} \mathrm{C}$ for 30 seconds each, followed by a final extension step lasting 7 minutes at $72^{\circ} \mathrm{C}$ and cooling to $4^{\circ} \mathrm{C}$. Polymerase chain reaction amplification products were purified with Calf intestinal phosphatase/Exonuclease I (New England Biolabs) and sequenced on an ABI 3730 DNA Analyzer (Applied Biosystems). We analyzed DNA sequences using SeqScape v2.6 (Applied Biosystems) for allelic discrimination, which was used to determine genotypes (electropherograms available in Appendix 1).

\section{Statistical analyses}

We assessed the deviation of genotype frequencies from the Hardy-Weinberg equilibrium using a $\chi^{2}$ analysis. The disease allele frequency in the population was estimated using the usual 95\% confidence interval (CI) for a binomial proportion, without a continuity correction. We used the delta method ${ }^{18}$ to estimate population genotype frequencies. Calculations were performed using R software. ${ }^{19}$

\section{Results}

Sequencing of SI identified a novel homozygous frameshift mutation in the proband NM_001041.3: c.273_274delAG (p.Gly92Leufs*8). No other pathologic variants were identified. This early frameshift in the fourth of SI's 48 exons affects the gene's only transcript and is therefore predicted to result in complete loss of enzyme expression (Figure 3). This allele is not represented in the data set of the 1000 Genomes Project (www.1000genomes .org), nor in the National Heart, Lung, and Blood Institute's Exome Variant Server (http://evs.gs .washington.edu/EVS), which comprises data from 13000 people of European or African descent.

From the 128 anonymized samples from Inuit controls living in the Canadian Arctic, we identified a further 2 homozygous and 40 heterozygous individuals. The observed allele frequency of this mutation in our sample is $17.2 \%$ (44 of 256 total alleles; binomial 95\% CI $12.6 \%-$ $21.8 \%$ ). The $\chi^{2}$ analysis confirmed the HardyWeinberg equilibrium $\left(p=0.3_{1}\right)$. There were no significant between-region deviations from the above allele frequencies. If we assume the absence of other common mutations, the expected Inuit prevalence of congenital sucraseisomaltase deficiency related to this specific mutation is estimated to be $3.0 \%$ (95\% CI 1.4\%$4.5 \%$ ). The carrier rate is estimated to be $28.5 \%$ (delta-method 95\% CI 22.4\%-34.5\%).

\section{Interpretation}

Our results show a common mutation, $S I$ c.273_274delAG, to be responsible for the high prevalence of congenital sucrase-isomaltase deficiency among people of Inuit descent. The predicted homozygosity rate for this mutation, $1.4 \%-4.5 \%$, is just below previous prevalence estimates of $5 \%-10 \% .^{10,11}$ Factors likely to account for the difference could include sampling bias, geographic variations in allele frequency or the presence of other (as-yet unidentified) mutations. Although our study sample spanned the Canadian Arctic, allele frequencies are likely to vary regionally and by population, and further study is required to assess the geography of congenital sucrase-isomaltase deficiency. The broad geographic span of this condition in Inuit people suggests an ancient founder mutation, although the condition itself only recently emerged (in the

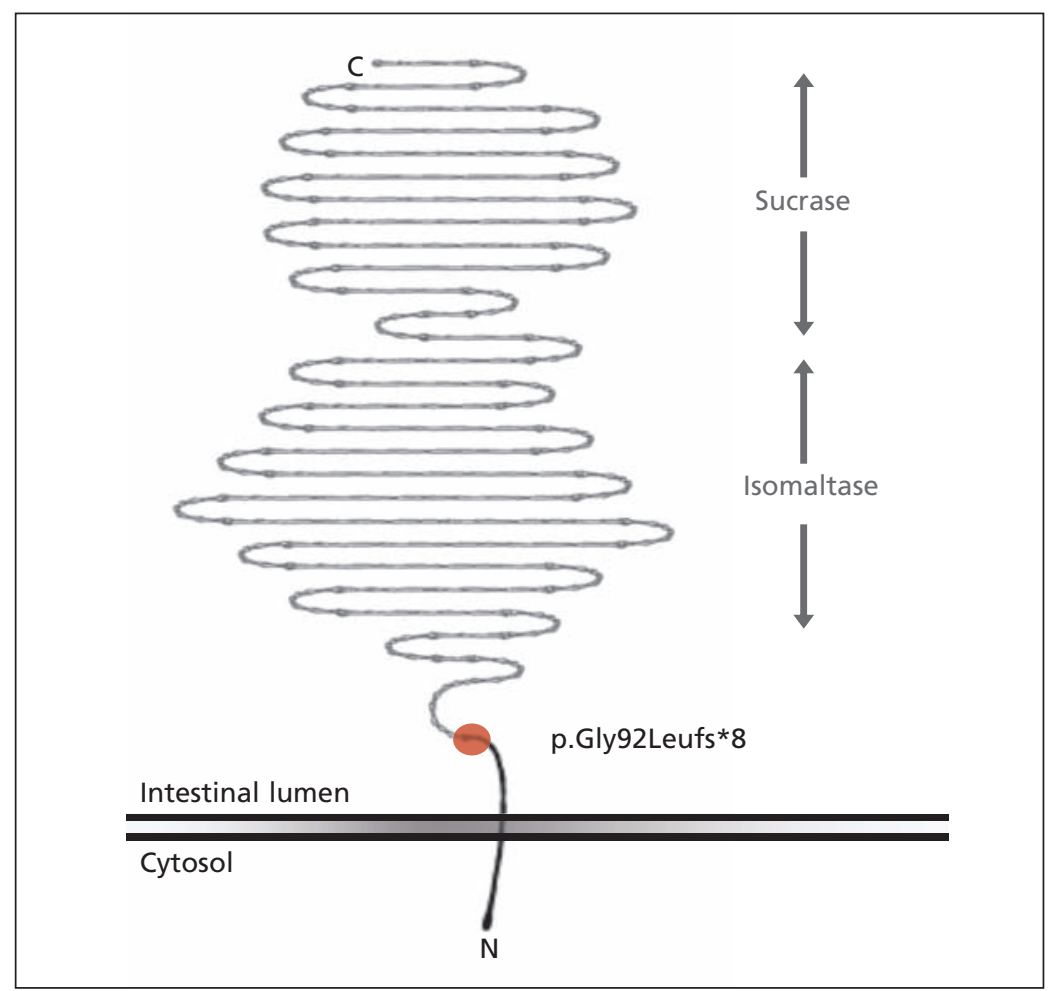

Figure 3: Sucrase-isomaltase is located at the brush-border membrane of the small intestine. Enzymatic domains are in the gut lumen, connected to the cellular membrane by a short linker sequence. The c.273_274delAG mutation (red circle) results in disruption of the usual reading frame (p.Gly92Leufs*8), completely abolishing both enzymatic activities (depicted in grey). Owing to nonsense-mediated decay, there is a high likelihood that the resulting messenger RNA product is targeted for degradation (i.e., is not translated and is functionally null). 
1960s) as a recognized health issue. This was likely as a consequence of the changing diet of the Inuit, which is traditionally (but not contemporarily) low in carbohydrates. ${ }^{20-22}$ In that respect, congenital sucrase-isomaltase deficiency presents a rare example of a gene-environment interaction under novel evolutionary pressures.

The severe presentation described in our proband likely reflects an underlying genotypic vulnerability (i.e., a complete lack of enzymatic activity caused by homozygous truncating mutations) exacerbated by early and prolonged exposure to dietary sucrose. Patients with milder mutations or lesser sucrose exposure would be expected to have variably milder phenotypes. Whereas congenital sucrase-isomaltase deficiency is considered a recessive disorder, the possibility of symptomatic carriers is an intriguing and unanswered question. In the absence of a second mutation, heterozygous carriers of the c.273_274delAG mutation should have about $50 \%$ normal sucrase-isomaltase activity (i.e., they should be able to cleave and absorb disaccharides to an extent). Nonetheless, reports of gastrointestinal symptoms in small numbers of people with only a single identifiable SI mutation do raise the question of whether carriers may have mild symptoms when exposed to sucrose. ${ }^{17,23}$ The availability of a noninvasive (molecular) test for congenital sucrase-isomaltase deficiency raises the possibility of a more systematic study of the phenotype, if any, in heterozygous people.

\section{Limitations}

One major limitation of this study is that the contribution of other SI mutations to the overall prevalence of congenital sucrase-isomaltase deficiency in Inuit people remains unknown. This could be addressed by sequencing SI completely in a larger group of Inuit people. SI mutations in various other populations are summarized in the Human Gene Mutation Database (www.hgmd.org) and the Leiden Open Variation Database (www.lovd.n1/3.0/home). Other major limitations include the following: the geographic distribution of the observed mutation, which is likely to be nonuniform, has not been specifically studied; the spectrum of clinical symptoms to be found in people homozygous for the c.273_274delAG mutation remains to be studied systematically in a suitable cohort; and the clinical phenotype of heterozygous carriers, if any, has not yet been assessed in detail. These limitations could be addressed through a larger founder mutation screening study, with collection of pertinent clinical data regarding dietary sucrose exposure and gastrointestinal symptoms.

\section{Conclusion}

We identified a common mutation, SI c.273_274delAG, to be responsible for the high prevalence of congenital sucrase-isomaltase deficiency among Inuit people. Our proband's presentation shows congenital sucrase-isomaltase deficiency to be a serious, potentially acute condition, for which timely recognition and start of appropriate therapy are paramount. This condition should therefore be considered in the differential diagnosis of Inuit children and adults with compatible symptoms (e.g., chronic diarrhea, failure to thrive and irritable bowel syndrome). Although breastfed infants with this condition are unlikely to present before weaning, some commercial formulas (including elemental and lactose-free formulas used in the management of suspected intolerance to cow's milk protein) do contain sucrose as their major carbohydrate component. As in our patient, use of elemental formula containing sucrose may result in a paradoxical worsening of symptoms.

Targeted mutation testing for the common $S I$ founder mutation may be a reasonable first-line diagnostic test for suspected congenital sucraseisomaltase deficiency in patients of Inuit descent. Patients homozygous for the c.273_274delAG mutation have a definite diagnosis of congenital sucrase-isomaltase deficiency, and can be spared intestinal biopsy and sucrose tolerance tests. If there is a strong clinical suspicion for this condition, dietary management should not be delayed while awaiting genetic results (i.e., it may be reasonable to consider empiric sucrose elimination while awaiting molecular confirmation). Because the existence of other SI disease alleles in this population has not yet been studied, negative or heterozygous (carrier) results should be viewed as inconclusive, and must be considered in the clinical context. At present, congenital sucrase-isomaltase deficiency is not a target of newborn or populationbased screening programs, although such screening may be technically feasible, medically beneficial and justifiable from a prevalence standpoint. At minimum, physicians caring for Inuit patients may wish to maintain a level of awareness of this common and readily treatable entity.

\section{References}

1. Treem WR. Congenital sucrase isomaltase deficiency. J Pediatr Gastroenterol Nutr 1995;21:1-14.

2. Semenza G, Salvatore A, Mantei N. Small-intestinal disaccharidases. In: Valle D, Beaudet AL, Vogelstein B, et al., editors. OMMBID: the online metabolic \& molecular bases of inherited diseases. New York: McGraw-Hill; 2013. Available: http ://ommbid.mhmedical.com/content.aspx?bookid=474\&Sectionid $=45374056$ (accessed 2014 Sept. 4).

3. Muldoon C, Maguire P, Gleeson F. Onset of sucrase-isomaltase deficiency in late adulthood. Am J Gastroenterol 1999;94: 2298-9.

4. Ringrose RE, Preiser H, Welsh JD. Sucrase-isomaltase (palatinase) deficiency diagnosed during adulthood. Dig Dis Sci 1980;25:384-7. 
5. Karnsakul W, Luginbuehl U, Hahn D, et al. Disaccharidase activities in dyspeptic children: biochemical and molecular investigations of maltase-glucoamylase activity. J Pediatr Gastroenterol Nutr 2002;35:551-6.

6. Treem WR, McAdams L, Stanford L, et al. Sacrosidase therapy for congenital sucrase-isomaltase deficiency. J Pediatr Gastroenterol Nutr 1999;28:137-42.

7. Lücke T, Keiser M, Illsinger S, et al. Congenital and putatively acquired forms of sucrase-isomaltase deficiency in infancy: effects of sacrosidase therapy. J Pediatr Gastroenterol Nutr 2009;49:485-7.

8. Peterson ML, Herber R. Intestinal sucrase deficiency. Trans Assoc Am Physicians 1967;80:275-83.

9. McNair A, Gudmand-Hoyer E, Jarnum S, et al. Sucrose malabsorption in Greenland. BMJ 1972;2:19-21.

10. Gudmand-Høyer E, Fenger H, Kern-Hansen P, et al. Sucrase deficiency in Greenland: incidence and genetic aspects. Scand J Gastroenterol 1987;22:24-8.

11. Ellestad-Sayed JJ, Haworth J, Hildes J. Disaccharide malabsorption and dietary patterns in two Canadian Eskimo communities. Am J Clin Nutr 1978;31:1473-8.

12. Bell RR, Draper H, Bergan J. Sucrose, lactose, and glucose tolerance in northern Alaskan Eskimos. Am J Clin Nutr 1973; 26: 1185-90.

13. Ellestad-Sayed JJ, Haworth J. Disaccharide consumption and malabsorption in Canadian lndians. Am J Clin Nutr 1977;30:698-703.

14. Treem WR. Clinical aspects and treatment of congenital sucrase-isomaltase deficiency. J Pediatr Gastroenterol Nutr 2012;55(Suppl 2):S7-13

15. Perman JA, Barr RG, Watkins JB. Sucrose malabsorption in children: noninvasive diagnosis by interval breath hydrogen determination. J Pediatr 1978;93:17-22.

16. Stenson PD, Mort M, Ball EV, et al. The Human Gene Mutation Database: building a comprehensive mutation repository for clinical and molecular genetics, diagnostic testing and personalized genomic medicine. Hum Genet 2014;133:1-9.

17. Uhrich $\mathrm{S}, \mathrm{Wu} \mathrm{Z}$, Huang J-Y, et al. Four mutations in the SI gene are responsible for the majority of clinical symptoms of CSID. J Pediatr Gastroenterol Nutr 2012;55(Suppl 2):S34-5.

18. Oehlert GW. A note on the delta method. Am Stat 1992;46:27-9.

19. R Core Team. R: A language and environment for statistical computing. R Foundation for Statistical Computing, Vienna, Austria; 2014. Available: www.r-project.org (accessed 2014 Sept. 12).

20. Berti PR, Hamilton S, Receveur O, et al. Food use and nutrient adequacy in Baffin Inuit children and adolescents. Can J Diet Pract Res 1999;60:63-70.
21. Sheehy T, Roache C, Sharma S. Eating habits of a population undergoing a rapid dietary transition: portion sizes of traditional and non-traditional foods and beverages consumed by Inuit adults in Nunavut, Canada. Nutr J 2013;12:70.

22. Langlois KA, Findlay LC, Kohen DE. Dietary habits of Aboriginal children. Health Rep 2013;24:3-7.

23. Sander P, Alfalah M, Keiser M, et al. Novel mutations in the human sucrase-isomaltase gene (SI) that cause congenital carbohydrate malabsorption. Hum Mutat 2006;27:119.

Affiliations: Department of Genetics (Marcadier), Children's Hospital of Eastern Ontario; Division of Gastroenterology, Hepatology and Nutrition (Boland), Children's Hospital of Eastern Ontario; Department of Pediatrics (Boland, Issa, Geraghty, Lines), University of Ottawa and Children's Hospital of Eastern Ontario Research Institute, Ottawa, Ont.; Department of Pediatrics (Scott, Wu), University of Washington, Seattle, Wash.; Robarts Research Institute (McIntyre, Hegele), Schulich School of Medicine and Dentistry, Western University, London, Ont.; Metabolics (Geraghty, Lines), Children's Hospital of Eastern Ontario, Ottawa, Ont.

Contributors: Julien Marcadier, Margaret Boland, C. Ronald Scott, Kheirie Issa, Michael Geraghty and Matthew Lines contributed substantially to the study conception and design. C. Ronald Scott and Zaining Wu performed molecular analysis in the proband. Robert Hegele and Adam McIntyre performed molecular analysis in the control samples. Julien Marcadier and Matthew Lines prepared the manuscript. All of the authors revised the manuscript, gave final approval to the manuscript submitted for publication and agreed to act as guarantors of the work.

Funding: Robert Hegele receives funding from the Canadian Institutes of Health Research. C. Ronald Scott and Zaining $\mathrm{Wu}$ receive funding from QOL Medical. The funding sources had no role in study design, data collection or analysis, manuscript preparation, or the decision to submit the article for publication.

Acknowledgements: The authors wish to acknowledge the contribution of the patient and family, without whom this work could not have been performed. The expert assistance of biostatistician Dr. Nick Barrowman is gratefully acknowledged.

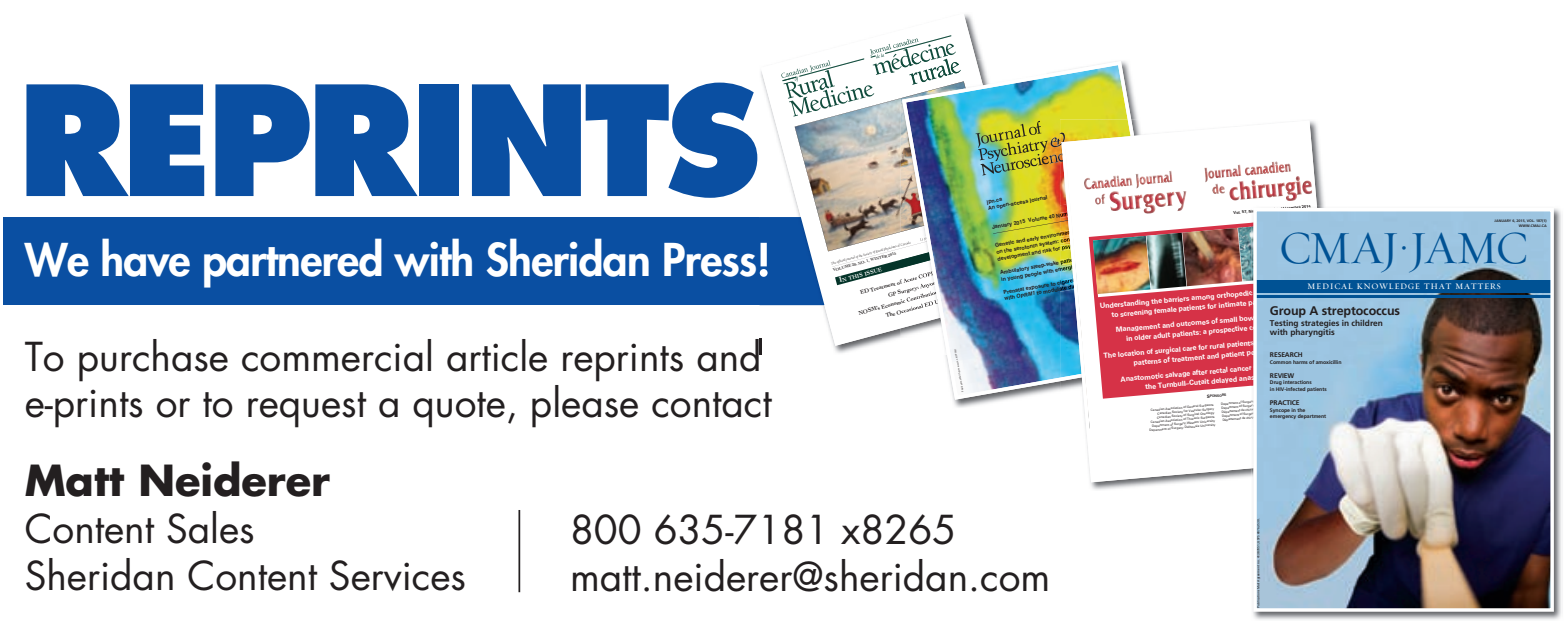

